attempted to examine relationship between perception of work-related stress and ill-health symptoms among the study sample.

Methods Responses from 81 nurses from three hospitals in Mumbai were studied.

'Stress Scale' was designed with the help of two survey instruments - 'Nurses Stress Scale' developed in 1981 by Grey-Toft and 'A to $Z$ test on the occupational sources of stress" developed by Asis K.Chakrabarti, ex-Director (Industrial Psychology) at Central Labour Institute, Mumbai.

Questionnaire method of data collection was adopted ensuring absolute confidentiality to protect identity, to ensure honesty in responding, and to obtain a reasonable response rate.

Statistical analysis of correlation was utilised to verify the results to prove the relationship between the perception of stress and ill-health symptoms among hospital nurses.

Results There exists a significant positive correlation between perception of occupational stress and psychosomatic symptoms among nurses. Psychosomatic disorders like backache, neck stiffness, and increased consumption of caffeinated products significantly increased in nurses having higher stress scores.

Discussion Moderate levels of stress were seen in a majority of nurses. It has been established that incidence of psychosomatic illness increases with the level of stress. Healthcare organisations need to urgently take preemptive steps to counter this problem in view of acute shortage of trained nurses. Without a comprehensive plan to deal with the issue, the problem may escalate into risks to patients and other consumers.

\section{PREVALENCE OF BURNOUT SYNDROME AMONG SURGICAL RESUSCITATION STAFF AT THE CHU SYLVANUS OLYMPIO (TOGO)}

${ }^{1} \mathrm{~K}$ Kara-Peketi*, ${ }^{1}$ YA Agbobli, ${ }^{1} \mathrm{~L}$ Djlogou, ${ }^{2} \mathrm{~F}$ Pandao. ${ }^{1}$ University of Lomé (TOGO); ${ }^{2}$ Pôle santé travail environnement et recherche (TOGO)

\subsection{6/oemed-2018-ICOHabstracts. 1646}

Introduction Burn out or burnout syndrome is a state of emotional exhaustion, dehumanisation of relationship to other, and decreased performance in response to chronic occupational stress.

Methods This is a descriptive and analytical cross-sectional study carried out among the practitioners of all the resuscitation departments of the CHU Sylvanus Olympio in Lomé.

Results The caregivers were divided into 11 physicians, 9 medical interns, 7 senior anaesthesia technicians, 1 resuscitation anaesthesia master, 50 state nurses, 1 masseur and physiotherapist. $35(44.30 \%)$ had a high level of emotional exhaustion. Burn out was found in $69.60 \%$ of caregivers, of whom 17 (21.50\%) had a moderate burnout and 3 (3.80\%), a high level of burn out. The causes significantly related to the occurrence of burn out were: lack of resources (diagnostic and therapeutic tools $)(\mathrm{p}=0.00005)$, reduced staff size $(p=0.00004)$, poor organisation of the service $(p=0.0004)$.

Discussion In our study, the prevalence of burnout was $69.60 \%$ of the nursing staff. In Morocco, AOUNTI Lotfi found in 2014 that $79.10 \%$ of caregivers working in the resuscitation departments of the anaesthesia resuscitation department of the CHU Hassan II in Fez were burning out.

\section{8 PSYCHOSOCIAL FACTORS IN MEDICAL STUDENTS PREDICT HIGHER BURNOUT LEVELS}

'D Mijakoski*, 'J Karadzinska-Bislimovska, 'S Stoleski, 'J Minov, ${ }^{2}$ A Stambolieva. ${ }^{1}$ Institute of Occupational Health of RM - WHO CC, Skopje, R. Macedonia; ${ }^{2}$ Medical Faculty, University Ss. Cyril and Methodius, Skopje, R. Macedonia (student)

\subsection{6/oemed-2018-ICOHabstracts. 1647}

Introduction The aim of the study was to determine stress factors related to medical education as predictors of burnout in medical students (MS) in the 5th year of studying, just before entering the world of work.

Methods Actual cross-sectional study was conducted by the Institute of Occupational Health of RM, including 165 MS in the 5th year of medical studies. Medical Student Stressor Questionnaire, Maslach Burnout Inventory, and Socio-economic and Studying Conditions Questionnaire were used. Multiple regression models were tested to examine the associations of stress factors related to medical education to burnout dimensions controlling for age, learning hours/week, and interpersonal relationships with parents/friends.

Results Bivariate analyses showed significant positive correlations of burnout dimensions with all domains of MS stressors. Emotional exhaustion demonstrated significant positive correlations with learning hours/week $(r=0.234, \mathrm{p}=0.003)$, and poorer interpersonal relationships with parents $(r=0.193$, $\mathrm{p}=0.014)$ and friends $(r=0.343, \mathrm{p}<0.001)$, while depersonalization only with poorer interpersonal relationships with friends $(r=0.258, \quad \mathrm{p}=0.001)$. Multiple regression analyses revealed that domain Academic related stressors (examination systems, academic schedule, getting poor marks, high-self expectation to do well, large amount of content to be studied, lack of time, etc.) (Standardised Beta $=0.359, \mathrm{p}=0.006$ ), poorer interpersonal relationships with friends (Standardised Beta $=0.244, p=0.001$ ), and learning hours/week (Standardised Beta $=0.140, p=0.044)$ were significant predictors of higher emotional exhaustion $\left(R^{2}=0.418\right)$. On the other hand, only poorer interpersonal relationships with friends positively predicted depersonalization (Standardised Beta $=0.197, \mathrm{p}=0.019$ ) $\left(R^{2}=0.159\right)$.

Discussion Actual study shows that psychosocial factors in MS entering the world of work are related to higher burnout scores. Preventive strategy oriented towards improvement of health and safety at work in physicians should involve measures for tackling academic related stressors in MS in order to reduce later burnout development.

\section{EVIDENCE THAT A STATE-WIDE PAID SICK LEAVE POLICY REDUCES OCCUPATIONAL INJURIES AND ILLNESSES}

${ }^{1,2}$ Devan Hawkins. 'University of Massachusetts Lowell, MA, USA; ${ }^{2}$ Massachusetts Department of Public Health, Boston, MA, USA

\subsection{6/oemed-2018-ICOHabstracts. 1648}

Introduction Unlike almost all other developed countries, paid sick leave is not mandatory for employers in the United States. Several states and municipalities have introduced paid sick leave policies. The first states to introduce such a policy was Connecticut, which passed a law requiring that employers offer 'service workers' one hour of paid sick leave for every 